\title{
LAS CAMPAÑAS POLÍTICAS DE LOS DIPUTADOS FEDERALES EN MÉXICO. ESFUERZOS BASADOS EN LOS CANDIDATOS Y EN LOS PARTIDOS
}

\author{
FEDERAL DEPUTY CAMPAIGNING IN MÉXICO. \\ PERSONAL AND PARTY BASED EFFORTS
}

\section{LES CAMPAGNES POLITIQUES DES DÉPUTÉS FÉDÉRAUX AU MEXIQUE. LES EFFORTS DES CANDIDATS ET CEUX DES PARTIS}

\author{
JoY K. LANGSTON \\ Centro de Investigación y Docencia Económicas \\ joy.langston@cide.edu
}

Resumen: Este artículo analiza las distintas formas en las que los candidatos mexicanos al Congreso llevan a cabo sus campañas en distritos electorales uninominales. Con este propósito, se estudian tanto los incentivos de los líderes de partido, como la fuerte probabilidad de que los diputados y los senadores regresen a sus localidades para seguir con sus carreras políticas y, por tanto, el estudio no se limita ni a los efectos del sistema electoral ni a los periodos de mandato. El artículo sostiene que las teorías que sólo toman en cuenta las reglas electorales soslayan tanto la importancia de la dirigencia del partido, como las diferentes maneras en las que los diputados federales que pretenden cargos en el gobierno pueden continuar sus carreras políticas. A partir de una base de datos de las actividades de campaña de una muestra de candidatos de los tres principales partidos políticos de México, la primera parte del artículo plantea que los candidatos de mayoría tienen un papel activo en las campañas. En la segunda, el artículo explica que una vez que han hecho campaña en distritos competitivos y que han adquirido más experiencia personal, los candidatos emprenden actividades de votación más personales. Sin embargo, las oficinas nacionales de partido también participan activamente en las campañas federales de diputados y senadores, lo cual pone de relieve la naturaleza mixta de las campañas modernas. 
Palabras clave: Campañas, voto personal, partidos políticos, carreras políticas.

Abstract: This paper explores how Mexican congressional candidates campaign in single-member-districts. To do so, it looks beyond the effects of the electoral system and single term limits and examines both party leaders' incentives and the strong likelihood that deputies will return to their locality to continue their political careers. We argue that theories that only examine electoral rules miss the crucial input of the party leadership as well as different ways that office-seeking deputies can continue career trajectories. With a database on the campaign activities for a sample of the candidates from the three major parties in Mexico, we show first, that plurality candidates are active campaigners; and second, that running in competitive districts and holding greater personal experience lead to more personal vote type activities. Nonetheless, national party offices are also active participants in federal deputy campaigns -underlining the mixed nature of modern campaigning.

Keywords: Compaigns, personal vote, political parties, political careers.

Résumé: L'article analyse les diverses façons dont les candidats mexicains mènent leurs campagnes dans les circonscriptions électorales uninominales. À cette fin, on considère les motivations des dirigeants des partis aussi bien que la haute probabilité que les députés et les sénateurs reviennent à leurs communautés pour y poursuivre leur carrière politique. C'est pourquoi l'analyse va au-delà des effets du système électoral et des durées des mandats. L'article propose que les théories qui ne tiennent compte que des règles des élections négligent l'importance des dirigeants du parti et celle des multiples manières dont les candidats à des postes politiques peuvent continuer leur carrière. En utilisant des données sur les activités dans les campagnes d'un échantillon de membres des trois partis politiques les plus importants au Mexique, la première section de l'étude montre que les candidats dans les circuits plurinominaux jouent un rôle important pendant les campagnes. La seconde explique, à son tour, qu'une fois qu'ils ont mené leur campagne dans des districts où la concurrence est forte et qu'ils ont consolidé leur expérience individuelle, ces candidats peuvent entreprendre des activités plus personnelles. Cependant, les structures nationales des partis participent elles aussi d'une manière décisive aux campagnes des députés et des séna- 
teurs fédéraux, ce qui met en évidence la nature mixte de celles-ci à l'heure actuelle.

Mots clefs: Campagnes, vote personnel, partis politiques, carrières politiques.

Traducción de Bernardo Mabire

Fecha de recepción: junio de 2017

Fecha de aceptación: abril de 2018

$B$

STE ARTículo analiza los tipos de campaña que los candidatos legislativos llevan a cabo en Distritos Electorales Uninominales (DEU), cuando no pueden aprovechar la ventaja de cargo por los límites de mandato. Hace ya varias décadas, Mayhew puntualizó que la combinación de un sistema de distritos uninominales y el control del votante sobre los procesos de selección permitía que se establecieran vínculos más estrechos entre los políticos ambiciosos y los votantes de sus distritos, a causa del interés de los políticos por continuar sus carreras en el Congreso. ${ }^{1}$ Este vínculo electoral lleva a los candidatos legislativos que contienden en distritos de mayoría a buscar el voto personal. Esto significa que recurren a sus propios esfuerzos de campaña, tratan de establecer una comunicación directa con el electorado y utilizan tanto su imagen personal como su reputación. ${ }^{2}$

Si hacemos a un lado las reglas electorales, una de las causas más importantes del voto personal es la ventaja que se 1974.

${ }^{1}$ Congress: The Electoral Connection, New Haven, Yale University Press,

${ }^{2}$ S. Bowler y D. M. Farrell, "Electoral Institutions and Campaigning in Comparative Perspective: Electioneering in European Parliament elections", European Journal of Political Research, vol. 50, núm. 5, 2011, pp. 668-688; B. Cain, J. Ferejohn y M. Fiorina, The Personal Vote. Constituency Service and Electoral Independence, Cambridge, Harvard University Press, 1987; J. M. Carey y M. S. Shugart, "Incentives to Cultivate a Personal Vote: A Rank Ordering of Electoral Formulas", Electoral Studies, vol. 14, núm. 4, 1995, pp. 417-439. 
deriva de haber ocupado un cargo público. Contender de nuevo por el mismo cargo ofrece varias ventajas al político que busca reelegirse, entre las que se incluye un mayor reconocimiento de su nombre entre los votantes, así como la posibilidad de atribuirse el mérito de haber implementado diferentes políticas o de conseguir más recursos para sus distritos. ${ }^{3}$ En un sistema de mayoría, la posibilidad de contender por el mismo cargo en el siguiente ciclo de alguna manera incide en que los políticos que ocupan el cargo traten de consolidar su imagen y su buen desempeño, pues usarán sus propias actividades para impulsar sus campañas.

En otros sistemas electorales, como en los Sistemas de Representación Proporcional de Listas Cerradas (sRPLC), en los cuales el votante no puede cambiar el orden de los nombres en las boletas electorales, los candidatos no pueden mejorar sus posibilidades electorales mediante la promoción de su propia imagen. En estos casos, los votantes tienden a enfocarse en los partidos y no en los candidatos individuales, pues las propuestas presentadas en las campañas de publicidad emprendidas por un partido nacional suelen centrarse, las más de las veces, en objetivos políticos públicos de interés general, lo cual debilita la conexión directa entre el votante y el representante. ${ }^{4}$

Sin embargo, se ha prestado poca atención a las maneras en las que los candidatos y los partidos llevan a cabo sus campañas en las democracias de mayoría directa que no cuentan con ventaja de cargo. Según Canache, Mondak y Cabrera, ${ }^{5}$ en México los incentivos para que los candidatos busquen el voto personal se ven reducidos por dos razones principales.

${ }^{3}$ A. Gelman y G. King, "Estimating Incumbency Advantage without Bias", American Journal of Political Science, vol. 34, núm. 4, 1990, pp. 11421164; Mayhew, op. cit.

${ }^{4}$ Bowler y Farrell, art. cit.; J. A. Karp y S. A. Banducci, "Party Mobilization and Political Participation in New and Old Democracies", Party Politics, vol. 13, núm. 2, 2010, pp. 217-234.

5 "Voters and the Personal Vote: A Counterfactual Simulation", Political Research Quarterly, vol. 53, núm. 3, 2000, p. 666. 
La primera es que los funcionarios electos no tienen un incentivo "inmediato" para tratar de establecer una comunicación directa con los votantes, puesto que no pueden reelegirse en el próximo mandato y la idea central que subyace en el voto personal es que los legisladores están motivados por el deseo de ganar la reelección. ${ }^{6}$ La segunda razón estriba en que los límites de mandato "fomentan una lealtad inquebrantable con el partido", sobre todo cuando éste controla la selección de candidatos. En consecuencia, dado que los líderes de partido tienen más influencia en su carrera política futura que los votantes, el político por sí mismo no tiene una razón para cultivar una reputación personal. ${ }^{7}$ Además, como los candidatos no pueden regresar a la legislatura en el siguiente mandato, no pueden adjudicarse el trabajo que hicieron en el Congreso y les resulta más difícil (aunque no imposible) obtener recursos públicos para gastos discrecionales en sus distritos (corrupción). Ante las pocas posibilidades de acceder a recursos públicos, los potenciales donantes tienen menos razones para dar recursos a los candidatos federales legislativos. Esta reducción de fondos disminuye también la capacidad de los candidatos de mayoría para tratar de buscar el voto personal, incluso si tienen los incentivos para hacerlo.

Sin embargo, por la fuerte tendencia a regresar a los escenarios políticos subnacionales (tanto estatales como municipales) y al deseo de continuar una carrera política, los candidatos de mayoría pueden recurrir a su honestidad, preparación y al trabajo que han hecho para tratar de conseguir votantes. Si los candidatos consideran que hay una alta probabilidad de obtener un cargo en la política subnacional, entonces parece razonable esperar que muestren más interés en la promoción de su imagen entre los votantes locales, puesto que esto atrae la atención tanto de los votantes como de los líderes de partido. Además, los can-

${ }^{6}$ Cain, Ferejohn y Fiorina, op. cit.

${ }^{7}$ Canache, Mondak y Cabrera, art. cit. 
didatos pueden recurrir a varias actividades de bajo costo, como las campañas puerta a puerta o algunas herramientas tecnológicas, como los spots.

La discusión en torno a las reglas electorales, el cargo y el retorno a la escena política subnacional soslaya un elemento fundamental, cuando se trata de establecer el tipo de campaña, es decir el liderazgo de partido, porque, según el contexto institucional, los líderes de partido tienen incentivos que deben tomarse en cuenta para el análisis. Este artículo, por tanto, se propone contribuir a los estudios que contraponen las campañas políticas basadas en las personas a aquellas que se basan en el partido, pues sostiene que, en un sistema electoral de representación proporcional mixta con una sola vuelta para ambos niveles, los líderes de partido preferirían mantener el control sobre los recursos de campaña y la publicidad en los medios de comunicación durante las elecciones de mayoría. ${ }^{8}$ Para incentivar a los votantes y mantener la imagen del partido, los líderes de partido deben gastar valiosos recursos a fin de obtener una votación total significativa. Con este propósito, pueden promover sus promesas y programas para mantener cierta independencia de las campañas un tanto faltas de coordinación que se ponen en marcha en las contiendas de los 300 distritos uninominales. Si se toman en cuenta tanto los incentivos de los candidatos de campañas de los DEU como a los líderes nacionales de partido, se espera una combinación de los dos tipos de campaña que suelen llevarse a cabo en los sistemas con regla de mayoría; sin embargo, como no hay ventaja de cargo, también se espera que, mientras la oficina nacional del partido se ocupa de las estrategias de difusión en los medios de comunicación más importantes y de las apariciones políticas, los candidatos de distrito se enfoquen en promover sus habilidades personales y sus trayectorias entre los votantes.

${ }^{8}$ M. Shugart y M. Wattenberg, Mixed-Member. Electoral Systems. The Best of Both Worlds?, Nueva York-Oxford, Oxford University Press, 2001. 
México es un caso importante para estudiar las campañas electorales, porque demuestra la fuerte tendencia de retorno a la escena política subnacional y el impacto que tienen las actividades de campaña de bajo costo en el voto personal, en un contexto caracterizado por la imposición de restricciones institucionales considerables a este tipo de voto. ${ }^{9} \mathrm{El}$ estilo de campaña influye significativamente en el comportamiento de los candidatos una vez que son elegidos para el congreso: los que tienen posibilidades de ganar la contienda mediante sus propios esfuerzos y promoción de imagen, tienden a comportarse de manera más independiente con respecto del liderazgo de partido. Esta cuestión, que está relacionada con aquella de la selección de candidatos (la cual hemos discutido en otro artículo), es útil para establecer el comportamiento individual de los legisladores en el Congreso.

La autora de este artículo reunió datos de los cargos inmediatamente anteriores y de los cargos inmediatamente posteriores que los diputados ocupan una vez que dejan la Cámara de Diputados (la cámara baja del congreso mexicano). Se encontró que más del $70 \%$ de los candidatos de mayoría en México provienen de la política subnacional y casi el $70 \%$ de los diputados federales, cuyo cargo ha finalizado, regresan a esa misma esfera política. Para medir los esfuerzos de campa-

${ }^{9}$ Desde el año 2000 se ha prestado poca atención a las campañas para diputados federales en México. Sin embargo, pueden consultarse los trabajos de O. F. Díaz Jiménez, "Marketing político y profesionalización de las campañas electorales del Partido Acción Nacional y el Partido de la Revolución Democrática (1994 -2006)", Polis, vol. 11, núm. 1, 2015, pp. 119-168; J. L. Exeni, “Acción mediática en tiempo de elecciones”, en Y. Meyenberg (coord.), Dos de julio: reflexiones posteriores, México, FLACSOIIS-UAM-I, 2001; M. E. Meneses Rocha y J. Bañuelos Capistrán, Internet y campañas electorales en México. La oportunidad postergada, Toluca, Instituto Electoral del Estado de México, 2009; E. Tello-Leal, D. A. Tello-Leal y C. M. Sosa Reyna, "Reflexiones sobre el uso de las tecnologías de información y comunicación en las campañas electorales en México", Revista Virtual Universidad Católica del Norte, núm. 36, 2012, pp. 33-47; y M. M. Tosoni, "Notas sobre el clientelismo político en la Ciudad de México", Perfiles Latinoamericanos, vol. 29, núm. 1, 2007, pp. 47-69. 
ña de los candidatos de mayoría en México, se usaron datos de buscadores electrónicos a fin de reunir información de las actividades de campaña de una muestra de candidatos. Se encontró que la competencia electoral y la experiencia previa incrementan la voluntad y la habilidad de los candidatos para llevar a cabo actividades que les permiten comunicarse directamente con los votantes, lo cual es consistente con el modelo de voto personal.

\section{ESTADO DE LA CUESTIÓN Y EXPECTATIVAS}

El concepto de búsqueda de voto personal significa que los candidatos intentan ganar sus cargos mediante la promoción de sus habilidades personales, sus logros en cargos anteriores y sus vínculos con la comunidad. Además de enfatizar la ideología del partido o las plataformas programáticas, el candidato destaca lo que ha hecho en su cargo: si está en funciones, enfatizará lo que ha logrado durante su periodo y, si no está en funciones, pondrá de relieve lo que ha conseguido en cargos anteriores. ${ }^{10}$

Si bien hay varios factores que determinan el voto personal, el más importante es el tipo de reglas electorales y el deseo de contender para una reelección, según destacan Cain, Ferejohn y Fiorina en su libro citado. Si los votantes pueden elegir un legislador de manera individual cuando votan, entonces se puede esperar que los candidatos traten de atraer a estos electores por medio de sus actividades de campaña. Esto sucede tanto en los DEU, como en los SRPLC. En éstos, por otra parte, los candidatos tienen menos incentivos para promocionar de manera activa sus habilidades y logros personales en la campaña, pues los votantes no pueden cambiar el orden de los nombres en las boletas electorales. Antes bien, los candidatos dependen de la publicidad de su partido difundida en los medios de comunicación y,

${ }^{10}$ Bowler y Farrell, art. cit.; Cain, Ferejohn y Fiorina, op. cit. 
si hacen campaña, será para apoyar al partido. Por ejemplo, en las cinco circunscripciones plurinominales que hay en México, los candidatos de representación proporcional de listas cerradas no realizan actividades de campaña, porque no hay dos boletas electorales separadas, lo cual dificulta a los votantes identificar y elegir candidatos de las listas de partido.

Haber ocupado un puesto político incrementa el poder del voto personal en los regímenes electorales en los que los votantes pueden seleccionar a sus candidatos y guarda una relación estrecha con el voto personal, pues les permite a los candidatos que ya han ocupado el mismo puesto adjudicarse el crédito por el trabajo realizado. Según Gelman y King, en su artículo arriba mencionado, la ocupación de un puesto político se relaciona con la popularidad individual del político más que con la del partido. La habilidad de los representantes para llevar recursos a su distrito o trabajar en proyectos a largo plazo que lo beneficien disminuye si su tiempo para poner en marcha sus proyectos se limita a un solo mandato. Por ejemplo, en California el financiamiento de campaña se redujo significativamente, cuando se introdujeron los límites de mandato, pues al no poder regresar a sus puestos, los diputados federales no han podido seguir ofreciendo beneficios a largo plazo a los votantes. ${ }^{11}$ Entonces, parece razonable postular que la introducción de límites de mandato resulta en la reducción de captación de fondos en las elecciones de diputados federales y esto incide en que los candidatos dispongan de menos dinero para ganar el puesto.

Pese a la relevancia de los estudios en reglas electorales, se constata un determinismo un tanto excesivo en las predicciones que sólo toman en cuenta los efectos de estas reglas para estimar si se debe esperar una campaña personal o una cam-

${ }^{11}$ K. Daniel y J. R. Lott Jr., "Term Limits and Electoral Competitiveness: Evidence from California's State Legislative Races", Public Choice, vol. 90, núms. 1-4, 1999, pp. 165-84. 
paña de partido. ${ }^{12}$ En parte, esto tiene que ver con la fuerza de la política subnacional en las democracias federales latinoamericanas. Por ejemplo, si bien los políticos de Argentina y Brasil podrían reelegirse, se observa una fuerte tendencia a volver a la misma área o localidad para continuar sus carreras políticas después de haber ocupado uno o dos cargos en la cámara baja. Esto se debe a las condiciones favorables que ofrecen los escenarios políticos de más bajo nivel; ${ }^{13}$ pues si los políticos de partido pueden regresar a un subconjunto similar de votantes en la política local y estatal, entonces pueden establecer un vínculo más directo con los votantes. ${ }^{14}$ Así, muchos candidatos trabajan de manera intensa para ganarse el voto personal durante las campañas, de modo que puedan demostrar a los líderes de partido su habilidad para ganar votos y recordar a los votantes que conocen bien los problemas de la comunidad.

Con relativa frecuencia, los estudiosos del voto personal no toman en cuenta el costo de las campañas. Sin embargo, se observa que, con excepción de los SRPLC, es probable que los candidatos emprendan actividades intensas o de bajo costo,

12 D. Samuels, "Incentives to Cultivate a Party Vote in Candidate-centric Electoral Systems”, Comparative Political Studies, vol. 32, núm. 4, 1999, pp. $487-518$.

${ }^{13}$ Hay abundante bibliografía sobre el federalismo en Latinoamérica: para el caso argentino, puede consultarse, entre otros, K. Eaton, "Political Obstacles to Decentralization: Evidence from Argentina and the Philippines", Development and Change, vol. 32, núm. 1, 2001, pp. 101-127; para el caso brasileño, se sugiere el trabajo de D. Samuels, Ambition, Federalism, and Legislative Politics in Brazil, Nueva York, Cambridge University Press, 2003; y para el mexicano, se recomienda L. Flamand, The Vertical Dimension of Government: Democratization and Federalism in Mexico, Rochester, University, 2004.

14 Según Y. Kerevel (“[Sub]national Principals, Legislative Agents: Patronage and Political Careers in Mexico", Comparative Political Studies, vol. 48, núm. 8, 2015, pp. 1020-1050), el 62.9\% del PRI, el 60.2\% del PAN y el $72 \%$ de los representantes del PRD regresan a la escena subnacional al terminar un mandato de tres años. Probablemente, por los métodos de contabilización empleados, los porcentajes del PAN y del PRI sean inferiores a los de este trabajo. 
independientemente del tipo de sistema electoral. De otra parte, si las actividades para promover su aptitud para el cargo son excesivamente costosas, es menos probable que las lleven a cabo. Los candidatos en México recorren puerta por puerta las colonias de los distritos, buscan oportunidades de entrevistas, publican en redes sociales y producen spots de videos caseros para ser más reconocidos por los votantes y los líderes locales de los partidos. Algunas de estas actividades implican gastos y préstamos en especie para rentar camiones o pagar material impreso. Sin embargo, estos gastos son mucho menos onerosos que los anuncios de televisión. Las actividades intensas de bajo costo o aquellas que son relativamente baratas facilitan al candidato de mayoría la promoción de su imagen.

Como se ha señalado, debe tomarse en cuenta a los líderes de partido y su consigna por aumentar la popularidad del partido, el número de votos y las fuentes de los recursos. En su deseo por ganar la reelección o continuar sus carreras en un cargo diferente, quienes buscan puestos políticos en ocasiones pueden ir en contra de los intereses de los líderes de partido. ${ }^{15}$ En esta lógica, los incentivos de los líderes de partido difieren de los incentivos de los políticos que trabajan de manera individual y, hasta cierto punto, estas diferencias están determinadas por las reglas electorales. Por ejemplo, en los SRPLC, las diferencias tienden a ser minimizadas, porque los votantes emiten su voto a partir de la imagen de los partidos y no según los candidatos y sus partidos, como suele ocurrir en los sistemas de distritos uninominales. Cuando los votantes optan por un partido sobre otro, las identidades de los candidatos incluidos en la lista pierden importancia, lo cual hace que los incentivos de los legisladores en torno a muchos asuntos de política pública se alineen con los de los líderes de partido. Cuando los votantes pueden elegir entre candidatos

${ }^{15}$ G. W. Cox y M. D. McCubbins, Legislative Leviathan. Party Government in the House, Berkeley-Los Angeles, CA, University of California Press, 1993. 
claramente identificados con un partido, quienes pretenden un puesto político algunas veces deben votar contra sus líderes de partido, si sus representados así lo demandan. Esto puede llevar a una falta de disciplina en las votaciones que se llevan a cabo en el Congreso.

Los líderes de partido quizás prefieran restringir la acción independiente entre los representantes de su partido que están en el Congreso; para tal fin, pueden tratar de limitar el voto personal. Esto puede hacerse de muchas maneras: los jefes de partido pueden reducir el gasto de los candidatos, regular o prohibir sus apariciones en los medios de comunicación o reducir la duración de la campaña y los límites de gastos. Los dirigentes partidistas también pueden mantener ciertas reglas, tales como los límites de mandato, para tratar de reducir la conexión directa entre el votante y los representantes. Por ejemplo, cuando el partido controla el financiamiento público, como en el caso de México, los candidatos que contienden en distritos que no "ameritan" recursos de campaña tendrán poco que gastar y, por tanto, pocas esperanzas de conseguir otros financiamientos para su campaña. Por esta falta de recursos, puede ser más difícil para los candidatos promover su imagen personal, incluso en distritos uninominales. Por tanto, este artículo sostiene que, en el contexto mexicano, que tiene límite de mandato y una sólida organización partidista, los líderes de partido desempeñan un papel importante en las campañas electorales para el Congreso, incluso si los candidatos de mayoría trabajan duro y emplean actividades menos costosas para tratar de ganar votos en sus distritos.

Bowler y Farrell, en su estudio citado, distinguen tres mecanismos para ganar el voto personal: primero, la prestación de servicios en los distritos de los candidatos; segundo, su formación y su trayectoria política y, finalmente, su experiencia en la localidad, la cual les permite satisfacer mejor las necesidades de los votantes. Si podemos comprobar que los candidatos a diputados mexicanos llevan a cabo actividades para difundir esta información, entonces podemos argumentar 
que los candidatos que compiten para ocupar un puesto en el congreso federal están haciendo campaña con base en su reputación personal. Los esfuerzos de los partidos se midieron por medio del financiamiento de las campañas y el número de anuncios producidos.

Para probar con más detalle el argumento de que los políticos en un sistema de mayoría con límites de mandato buscarán el voto personal, se derivaron las implicaciones empíricas del argumento. Si los candidatos al Congreso tienden a promover su experiencia previa, su aptitud para el cargo y su voluntad para resolver problemas locales, entonces deberían llevar a cabo diferentes tipos de actividades que les permitan comunicar sus virtudes personales a los votantes locales. Además, el porcentaje de estas actividades debe ser más elevado en distritos competitivos, dado que los candidatos en los distritos perdidos tienen pocas razones para promover su imagen y sus capacidades políticas entre los votantes. Una implicación del argumento del regreso a la esfera política subnacional es que los candidatos con experiencia previa en este tipo de escenarios políticos (que incluye tanto cargos políticos municipales como estatales) deberían estar más dispuestos a llevar a cabo actividades que promuevan dicha experiencia que aquellos cuya experiencia política se sitúa en el escenario político federal.

Hipótesis 1: si los candidatos buscan el voto personal, entonces deberían emplear diversos tipos de tácticas electorales enfocadas en la comunicación personal con los votantes. Hipótesis 1a: si los líderes de partido participan en las campañas del congreso, entonces deberían realizar actividades que promuevan la imagen del partido, como, por ejemplo, la presencia en los medios de comunicación. Hipótesis 2: si los candidatos buscan el voto personal, entonces los que contienden en los distritos competitivos, en lugar de en los bastiones del partido o en los distritos que históricamente han sido imposibles de ganar para el partido (los cuales se definen más adelante), deberían emprender actividades de campaña más personalizadas. Hipótesis 3: si los candidatos con 
límite de mandato buscan el voto personal para regresar a la localidad, entonces los candidatos que tienen más experiencia previa en el escenario de política subnacional deberían recurrir a actividades de campaña más centradas en las problemáticas locales que sus contrapartes que sólo tienen experiencia federal previa.

Este trabajo se centra en las campañas de diputación federal en México que tuvieron lugar en 2009 y 2012, puesto que aquél fue el primer año electoral en el que se generalizó el uso de las redes sociales (vale la pena puntualizar que YouTube llegó a México en 2007) y porque éstas fueron las primeras elecciones en las que, por la Reforma electoral de 2008, los candidatos no pudieron difundir su propia publicidad en radio o televisión. En el siguiente apartado, se analizan los tipos de actividades electorales y se ofrecen datos de entrevistas con candidatos a diputados federales de los tres principales partidos de México, entre los que se incluyen tanto candidatos perdedores como ganadores. Para demostrar la fuerte tendencia de los candidatos a regresar al escenario de política subnacional, se presentan cifras tanto de los cargos inmediatamente anteriores de los candidatos, como de los cargos inmediatamente posteriores de los diputados, una vez que han dejado su puesto en la Cámara de Diputados.

\section{LA CAMPAÑA A LA DIPUTACIÓN FEDERAL MEXICANA}

La Constitución de México prohíbe la reelección consecutiva en todos los cargos legislativos y las presidencias municipales, así como cualquier reelección a las gubernaturas y la Presidencia, sean o no consecutivas. Los cargos para el Congreso se eligen según un sistema electoral mixto, 300 de los 500 diputados federales son elegidos por la vía de mayoría. Los restantes 200 se eligen a partir de las listas cerradas que cada partido presenta para los 40 lugares del Congreso que se asignan para cada una de las cinco circunscripciones electorales del país. Los votantes sólo tienen una boleta para elegir tanto 
a sus diputados de distritos uninominales como a sus candidatos de representación proporcional, de modo que, al elegir a su candidato en el distrito, también eligen a ese mismo partido en la lista regional cerrada de cuarenta personas. Según esta regla, los jefes de partido deberían presionar a los candidatos de mayoría a hacer campaña tanto como les sea posible, ya que la distribución de curules depende del número total de votos reunidos en una lista regional de distritos múltiples (circunscripción). La obtención de más votos (independientemente de si el candidato de distrito ganó) se traduce en más curules en la lista cerrada de 40 personas. En la práctica, sin embargo, esto no es así.

Respaldados por las reglas constitucionales establecidas para prohibir la reelección consecutiva, los líderes de los tres principales partidos de México han trabajado de manera diligente para atenuar el poder de los candidatos que buscan ocupar un cargo desde que empezó la transición a la democracia en México, a comienzos de la década de los noventa. Entre el 2000 y el 2013, se consideró de manera reiterada modificar la Constitución para permitir la reelección consecutiva; sin embargo, los líderes del Partido Revolucionario Institucional (PRI) y del Partido de la Revolución Democrática (PRD) no respaldaron la medida, a sabiendas de que ésta daría mucho más poder y autonomía a los miembros de su partido que tuvieran un cargo. ${ }^{16}$ Por las reformas de 2008, los candidatos federales ya no pueden usar en sus distritos pendones con su nombre y su fotografía, ni pueden contratar personalmente publicidad en radio o televisión. ${ }^{17}$ Hasta

16 A finales de 2013, se aprobó una reforma constitucional que permitía la reelección consecutiva y cuya implementación se proyectaba para 2021. Sin embargo, las regulaciones establecen que los candidatos pueden participar en una reelección en el siguiente término siempre y cuando contiendan por el mismo partido.

17 Antes de las reformas electorales de 2008, los candidatos podían pintar bardas y colgar pendones para difundir publicidad político-electoral. No obstante, en la actualidad, llevar a cabo este tipo de actividades se ha vuelto más difícil y está más regulado. Los candidatos no pueden co- 
las reformas de 2013, los candidatos que no estuvieran registrados por un partido reconocido ante las autoridades electorales no podían tener sus nombres impresos en la boleta.

Los partidos políticos mexicanos tienen mucha fuerza, si se comparan con otros partidos políticos de Latinoamérica. En la década de los noventa, los líderes de los tres principales partidos negociaron las reglas electorales que les dieron a los comités ejecutivos nacionales (CEN) de los partidos el control del financiamiento. El dinero para las campañas públicas no se canaliza de manera directa a los candidatos sino a los CEN de los partidos, los cuales se encargan de distribuirlo de manera un tanto arbitraria. Los candidatos a las diputaciones federales deben apegarse a un límite relativamente bajo de gasto que se incrementó de aproximadamente $\$ 80$ mil dólares estadounidenses en 2009 , a $\$ 100$ mil en 2012. Aunque en la práctica estos límites presupuestales son difíciles de monitorear, los límites en el gasto de campañas hacen que la puesta en marcha de campañas activas sea más complicada. ${ }^{18}$ Sin embargo, este tope de gastos de campaña no quiere decir que los candidatos reciban esta cantidad de su partido. Muchos candidatos reportaron que recibieron entre $\$ 35$ mil y $\$ 50$ mil dólares estadounidenses del CEN de su partido durante ese periodo, lo que equivale aproximadamente a la mitad del tope de gastos de campaña. Algunos candidatos pueden recaudar fondos considerables o gastar sus propios recursos para incrementar sus gastos en diferentes actividades, como

locar material publicitario en espacios públicos (en postes, por ejemplo) y deben pedir permiso a los dueños para colocar cualquier anuncio en su barda.

${ }^{18}$ Para el año 2006, los topes de gastos distritales fueron de $\$ 950186.10$ pesos mexicanos; para 2009, $\$ 812680.60$ pesos mexicanos; y para 2012, \$1 120373.61 pesos mexicanos. Para más información, consúltese los siguientes sitios electrónicos: http://www.ife.org.mx/documentos/DIR-SECRE/ gaceta_elec/gaceta94/5-G94-05.pdf, http://www.ife.org.mx/docs/IFE-v2 /DS/DS-CG/DS-SesionesCG/CG-acuerdos/2009/Enero /29enero/CGo 290109ap15.pdf, y http:/ / www.ife.org.mx/docs/IFE-v2/DS/DS-CG/DS-Se sionesCG/CG-acuerdos/2011/diciembre/CGex201112-16/CGe1612 11ap3.pdf 
la entrega de volantes, las campañas puerta a puerta y la contratación de equipos para que los ayuden a hacer campaña en todo el distrito electoral. ${ }^{19}$ Sin embargo, como los legisladores federales no pueden llevar recursos públicos a sus distritos, no se benefician de manera significativa de la recaudación de otros tipos de fondos. ${ }^{20}$

Es importante destacar que los partidos son responsables de las campañas que se difunden en radio y televisión (campañas por las que ellos ya no pagan) y que los propios partidos desempeñan un papel activo durante las campañas presidenciales. ${ }^{21}$ Según los tiempos del Estado, el número total de spots garantizados para cada partido depende del desempeño de éste en las elecciones de diputados federales. De ese total, a cada partido se permite usar el $30 \%$ del número total de spots en igualdad de condiciones. En elecciones para presidente, senadores y diputados federales del 2012, todos los partidos registrados tuvieron garantizada una parte equitativa de 56333000 mensajes en radio y televisión, lo cual constituyó

${ }^{19} \mathrm{Al}$ preguntar a un candidato con pocas esperanzas de ganar cuánto gasta regularmente en una campaña alguien que contiende para diputado federal, respondió que, aproximadamente, el dispendio ascendía, en 2009, a $\$ 5$ millones de pesos mexicanos, lo que equivale, más o menos, a \$400 mil dólares estadounidenses, lo cual podría ser una exageración. En ese mismo año de 2009, otro candidato reportó que recibió \$300 mil pesos mexicanos de su partido (aproximadamente \$27 mil dólares estadounidenses). Al preguntarle cómo había hecho campaña con tan poco dinero, éste respondió: "Tengo muchos amigos". Entrevista entre la autora y un candidato exitoso del Distrito Federal (ahora Ciudad de México), realizada el 29 de julio de 2011.

${ }^{20} \mathrm{En}$ varios escándalos recientes se ha inculpado a algunos presidentes municipales por sobornar a los líderes de las reuniones electorales en las que se elige a los candidatos. En particular, se los ha acusado de repartir más recursos a sus municipios, lo cual deja ver que, en realidad, los diputados tienen poca influencia.

${ }^{21}$ Según un informe de la Unión Europea, el IFE no pidió al PRI que hiciera públicos sus registros bancarios, cuando el partido fue acusado de comprar votos durante las elecciones de 2012, aun cuando la autoridad electoral tenía el poder para hacerlo. 
el $30 \%$ del número total de spots. ${ }^{22} \mathrm{El}$ otro $70 \%$ se dividió entre los partidos de acuerdo con su resultado del 2009 en el congreso federal. En total, los partidos tuvieron 26 minutos diarios para sus spots durante la campaña del 2012, ${ }^{23}$ lo cual se materializó en 96 spots diarios por partido (cada uno tuvo una duración de 30 segundos) que tuvieron que transmitirse en las 2335 estaciones de radio y televisión del país. Por tanto, no hay duda de que en México los partidos políticos son responsables de la publicidad en los medios de comunicación, la cual suele concentrarse en políticas y asuntos de índole nacional. Asimismo, los partidos contratan servicios de encuestas de opinión para el voto nacional y en muchas de las contiendas distritales. Los líderes de partido, en especial en las elecciones intermedias, debaten activamente en torno a las críticas y los temas más comentados por otras organizaciones electorales. La gráfica 1 permite apreciar los recursos económicos de los partidos políticos durante los años de campaña.

En 2012, el PRI tuvo más presupuesto que los otros dos grandes partidos gracias a su mejor desempeño en las elecciones federales para el Congreso de 2009, de modo que pudo destinar más recursos para sus candidatos en las contiendas electorales. Lamentablemente, por las prácticas de presentación de la información de campaña, es imposible saber cuánto dinero gastó cada candidato en su distrito de campaña. ${ }^{24} \mathrm{El}$ Partido Acción Nacional (PAN), el partido de centro-derecha, ocupaba la Presidencia durante las campañas de 2009 y 2012 y, como se muestra más adelante en las regresiones, es la variable excluida con la que los otros dos partidos se comparan.

Las oficinas de partido también contribuyen de manera más directa a las contiendas por los distritos. Primero, los CEN de los partidos establecen cuáles son los distritos prioritarios

22 INE, Memorias del Proceso Electoral Federal 2011-2012, en www.ine.mx

23 Idem.

${ }^{24}$ De 1997 a 2012, los partidos podían prorratear sus costos totales de campaña, si reportaban tales gastos a cada uno de los 300 distritos, para que éstos tuvieran también una cantidad desconocida del gasto del partido. 
del total de 300 y en ellos concentran más recursos (entrevista con María de las Heras, otrora experta de encuestas del PRI, el 22 de noviembre de 2001). Segundo, los CEN determinan un programa de acción para las campañas, en el cual se diferencian las regiones del país (entrevista con la diputada federal María de la Paz Quiñones, el 14 de junio de 2010, y entrevista con Humberto Cervantes del PRI, el 1 de junio de 2004). Finalmente, los partidos nacionales también destinan cierta cantidad de dinero a casi todos los candidatos: la secretaría de finanzas de las oficinas nacionales debe mantener el control sobre la cantidad que se gasta en cada distrito, pues esos gastos deben reportarse a la autoridad nacional electoral.

\section{GrÁfica 1}

Recursos públicos destinados a los partidos en 2009 y 2012

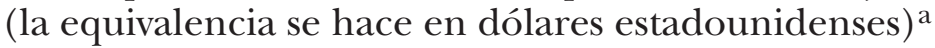

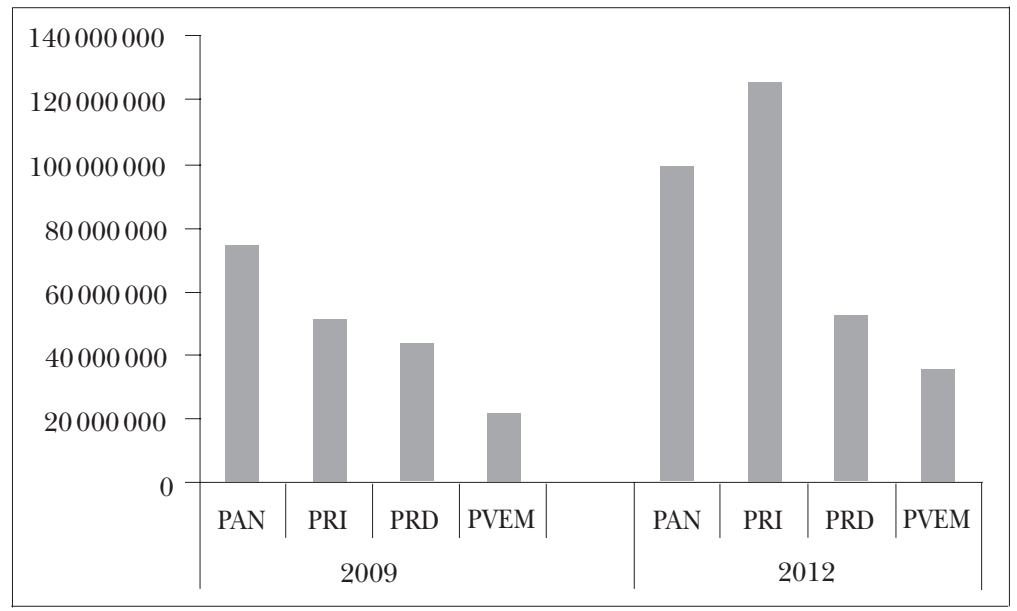

${ }^{\text {a }}$ Las elecciones para el Congreso de 2006 y de 2012 coincidieron con las presidenciales.

Fuente: http://www.ine.mx/archivos3/portal/historico/recursos/IF Ev2/DEPPP/PartidosPoliticosyFinanciamiento/DEPPP-financiamiento/ financiamientopublicopartidosnacionales/financiamiento-publico-97-17. pdf 
Durante el periodo cubierto en este artículo, el CEN de cada uno de los tres partidos principales envió representantes a los distritos para que ayudaran a los candidatos con las estrategias de campaña. Una parte importante del trabajo de estos representantes fue convencer a otras facciones del partido para que apoyaran al candidato (entrevista con los diputados del PRI, Lázaro Arias, el 6 de mayo de 2004, y Mario Zepahua, el 31 de mayo de 2004).

Con respecto de una acción más directa en las campañas distritales, varios entrevistados señalaron que, en general, los partidos participaron poco. Éste es un punto importante, pues si las campañas para el Congreso fueran dirigidas por los partidos, eso implicaría que el personal encargado de la organización es responsable de llevar a cabo las contiendas de mayoría relativa, lo cual, como mostraremos más adelante, no es el caso. Sin embargo, los partidos sí hicieron algunas contribuciones de manera directa en las campañas puerta a puerta, como, por ejemplo, distribuir volantes y otros materiales impresos que, en algunas ocasiones, incluían el nombre y la fotografía del candidato y, en otras, sólo llevaban el logo y los colores del partido (entrevista con el diputado federal Gustavo Madero, 2 de marzo de 2005). Según sus recursos, los CEN llevan a cabo varias encuestas de distrito durante la campaña (entrevista con la diputada federal María Araceli Vázquez Camacho, 10 de junio de 2010). Otros candidatos ganadores y perdedores insisten en que el CEN hizo poco o nada por sus campañas (entrevistas con los diputados del PRI Sandoval, en abril de 2002, y Raúl Mejía, el 27 de mayo de 2004). En general, como afirmó el entonces diputado Norberto Corella del PAN, hubo poco monitoreo de las estructuras del PAN y se evaluó muy poco cómo estaba resultando la campaña (entrevista, 23 de febrero de 2005). Los partidos también contribuyeron estatalmente en el pago de los trabajadores contratados, quienes, entre otras cosas, se encargaron de colocar pendones y distribuir volantes (entrevista con la diputada del Pan María de la Paz Quiñones, el 14 de junio de 2010). Sin embargo, estas actividades fueron en su mayo- 
ría realizadas por el equipo del candidato. La percepción general fue que las dependencias estatales de los partidos contribuyeron poco en las contiendas de mayoría relativa (entrevista a Humberto Cervantes, el 1 de junio de 2004). Los partidos nacionales tampoco contribuyeron mucho en dichas contiendas, pues su participación se limitó a la difusión de publicidad en los medios de comunicación nacionales.

\section{LA FUERTE TENDENCIA A REGRESAR}

AL ESCENARIO POLÍTICO SUBNACIONAL

Se examina aquí la información relacionada tanto con los puestos inmediatamente anteriores de aquellos que compitieron por un escaño para la diputación, como los puestos inmediatamente posteriores de los candidatos que ganaron sus escaños, lo cual nos permitirá demostrar el interés que tienen los políticos partidistas en comunicarse con los votantes dada la alta probabilidad de que regresen a la escena municipal o estatal. La información de 2006 y 2009 fue recopilada de los motores de búsqueda de internet, sobre todo de servicios de monitoreo de medios y blogs sobre política y comprende los cargos inmediatamente anteriores de los candidatos a diputados federales y los futuros cargos de los candidatos de los dos ciclos electorales examinados en este estudio. Los datos muestran claramente que, en México, así como en Argentina y Brasil, el escenario de la política subnacional ofrece a los políticos con ambiciones un entorno diverso en el que pueden buscar una carrera política a largo plazo.

En los sistemas federales, los gobernadores son los líderes del gobierno estatal y, con frecuencia, también están al frente de los partidos estatales. ${ }^{25}$ Así, los gobernadores controlan

${ }^{25}$ R. Hernández Rodríguez, El centro dividido: la nueva autonomía de los gobernadores, México, El Colegio de México, 2008; A. Giraudy, "The Politics of Subnational Undemocratic Regime Reproduction in Argentina and Mexico", Journal of Politics in Latin America, vol. 2, núm. 2, 2010, pp. 53-84. 
millones de dólares provenientes de fondos federales y estatales, cuya distribución obedece más a fines políticos que a la búsqueda del desarrollo. Los diputados que regresan al escenario de política subnacional y que han ganado una elección directa son un recurso valioso para los líderes políticos, sobre todo para los gobernadores. Los gobernadores ayudan a pagar las campañas, dado que les conviene tener tantos diputados en la cámara como sea posible a fin de promover las necesidades de sus estados en las asignaciones presupuestarias anuales y en otras legislaciones pertinentes. ${ }^{26}$

Un primer hallazgo estriba en que los políticos en México no son principiantes: antes de ganar las nominaciones, sólo alrededor de un $6.5 \%$ (PRI) y un $15.5 \%$ (PRD) de los candidatos provenía de puestos no políticos (maestros, líderes de organizaciones no gubernamentales, etcétera) y sólo entre el $4.1 \%$ (PAN) y el $12.6 \%$ (PRD) regresaron a puestos no políticos al término de sus periodos de gestión de tres años.

Las cifras en la tabla 1 muestran también que en México hay una fuerte tendencia a regresar a los estados, lo cual refuerza el argumento de que los candidatos quieren demostrar al gobernador de su partido y a la clase política local que pueden ganar votos y que, por tanto, merecen más oportunidades en el futuro. Para ganar estos votos, los diputados recurren a actividades de campaña orientadas a destacar su personalidad, su origen familiar, sus vínculos con la comunidad y su disposición de trabajar para los miembros de dicha comunidad. En los ciclos electorales estudiados, el $67 \%$ de los candidatos a diputado del PAN provinieron de cargos de la política subnacional y lo que más llama la atención es que el $71.2 \%$ de los diputados que dejaron la legislatura luego de un periodo regresaron al escenario de la política subnacio-

${ }^{26}$ En entrevista llevada a cabo el 15 de junio de 2004, Jesús María Ramón, exdiputado del PRI en Puebla, estado gobernado por el PRI, enumera los recursos que un gobernador usa para apoyar a un candidato a diputado de su partido. Este último obtiene dinero y recursos humanos tanto del gobierno como de las dependencias federales del estado; ayuda de los sindicatos (si los hay) y acceso a los medios de comunicación locales. 


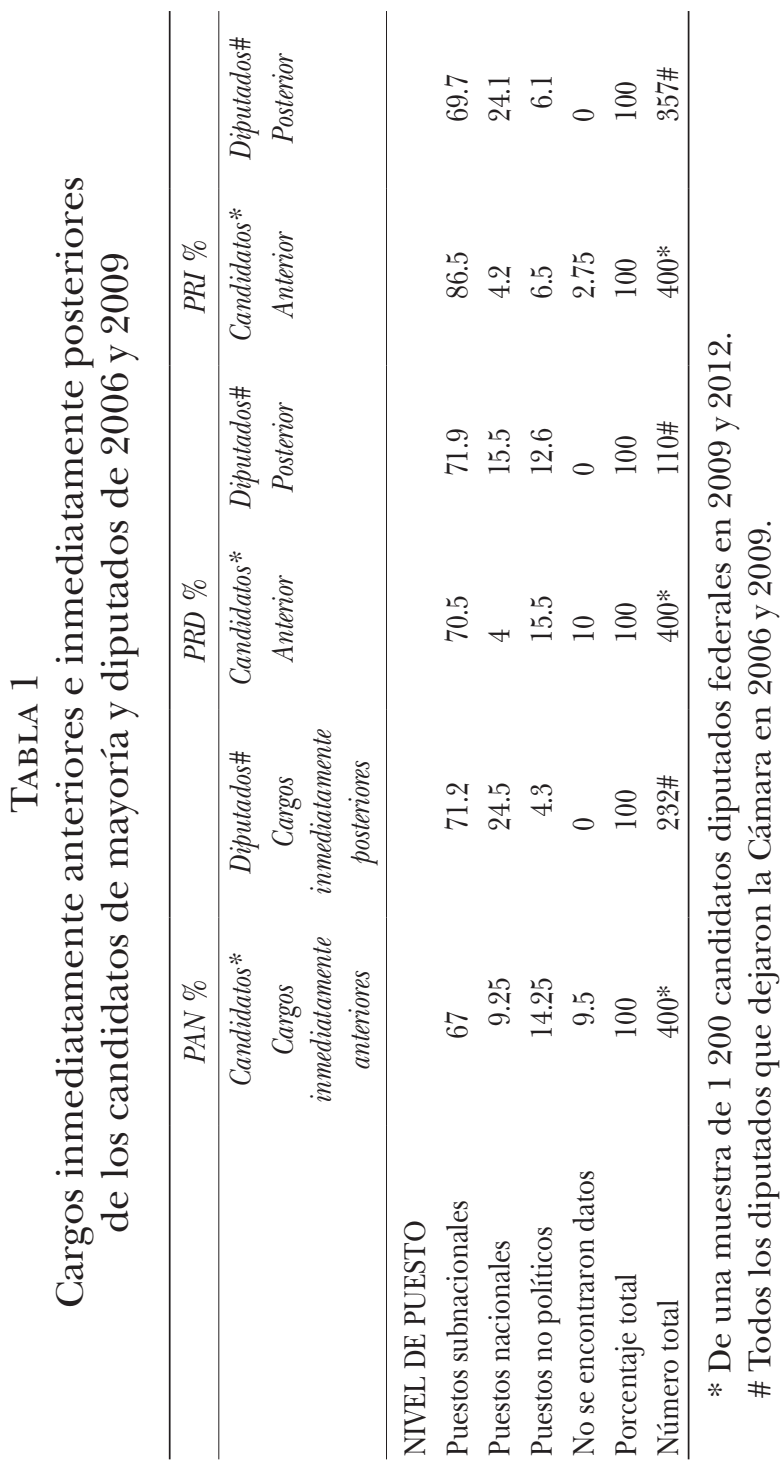


nal para su próximo cargo, aun cuando el PAN mantuvo la presidencia de 2000 a 2012 y, por tanto, tenía miles de puestos federales bajo su control. Las cifras de los candidatos del PRI y del PRD y de los diputados que dejaron la cámara son muy similares: los porcentajes oscilan entre el $60 \%$ para el PRI y $70 \%$ para el PRD. Incluso cuando el diputado ganador vuelve a su estado y hay un nuevo gobernador, todavía es muy probable que trabaje con un ejecutivo estatal de su partido. Además, los políticos más ambiciosos pueden usar su campaña electoral de tres meses para fortalecer su nombre e imagen ante un subgrupo similar de votantes. Los políticos mexicanos son profesionales que pasan décadas en puestos burocráticos, partidistas y de elección, aun cuando no cuentan con la estabilidad de la reelección. Hasta cierto punto, esta tendencia a regresar al escenario de la política subnacional nos ayuda a entender por qué los candidatos que compiten en distritos de mayoría del Congreso optan por campañas enfocadas en su persona. Este tipo de campañas permiten a los diputados comunicarse con los votantes para recordarles el trabajo que han hecho y prometerles que, mientras estén en el Congreso, apoyarán de manera significativa las necesidades del distrito en cuestión.

Para medir los esfuerzos de las campañas y probar las hipótesis antes señaladas, construimos una base de datos sobre las actividades de las campañas de mayoría correspondientes a 2009 y 2012 de los tres partidos más importantes de México. Los datos se obtuvieron de motores de búsqueda de internet. De un total de 1800 campañas de DSM (esta cifra se obtuvo, al multiplicar los 300 distritos de mayoría existentes por los tres partidos más importantes y luego por los dos periodos de elecciones), por cada uno de los dos ciclos de elecciones, se tomó una muestra representativa aleatoria de 200 distritos por cada partido y se obtuvo un total de $1200 .{ }^{27}$ Los

${ }^{27}$ Se puede argumentar que las actividades de cada candidato no se hicieron de manera independiente, porque los candidatos tenían que reaccionar a lo que hacían los otros contendientes en su distrito. Esto no 
300 distritos están representados en la muestra. Sin embargo, algunos fueron incluidos más de una vez en la base a causa de la distribución aleatoria de 200 de los 300 partidos por cada partido considerado de manera separada. Por el reducido número de distritos de mayoría (300), se optó por una selección aleatoria simple. Al probar la validez de la muestra, el porcentaje de población con acceso a servicios de salud es de 0.64 y en el universo de todos los distritos también es de 0.64. El número promedio de años de estudio en cada distrito (variable que fue utilizada en la muestra y no en la regresión) es 8.24 y en la base de distritos INEGI-IFE, correspondiente al 2010, es de 8.26.

Se buscó a cada uno de los candidatos de los distritos seleccionados en Google, YouTube, Facebook y en el portal de noticias financieras Infolatina. La búsqueda arrojó información sobre una gran variedad de actividades que se pueden encontrar en internet, como mítines, spots de televisión, recorridos por las colonias, entrevistas en medios de comunicación y el uso de redes sociales. ${ }^{28}$ Es importante señalar que la

constituye un problema serio, pues se toma en cuenta tanto la competencia electoral por distrito como otras variables políticas; por ejemplo, si el presidente municipal es del mismo partido que el candidato en cuestión.

28 Por ejemplo, Alfredo González González era líder de la Confederación Revolucionaria de Obreros y Campesinos (CROC) en Aguascalientes, cuando fue candidato por el PRI en las elecciones para diputados del segundo distrito de ese estado en 2012. González organizó reuniones con la gente de su sindicato y participó en un mitin con otros candidatos del PRI. Tenía tres páginas: https:/ /www.facebook.com/JoseAlfredoGonzalezG; http:/ / www.alfredogonzalez.org/; http://www.lja.mx/2012/05/ alfredo-gonzalez-ofrece-respeto-a-la-libre-expresion-y-defensa-permanente-de-la-clase-trabajadora/. González había sido diputado local y competido para ser candidato del PRI en la contienda para gobernador (que perdió) de ese estado en 2004. Se examinaron las siguientes páginas para recabar información en nuestra base de datos: líder del sector estatal, cargo estatal, diputado local, mitin, redes sociales: http://www. lja.mx/2012/05/llama-priismo-a-restar-votantes-a-partido-accion-nacional/; http:/ / www.hidrocalidodigital.com/local/articulo.php?idnota=9031; http:/ / www.proceso.com.mx/233547/otto-granados-8220un-malagradecido-8221-pri-de-aguascalientes; http://www.google.com.mx/url?sa=t 
campaña puerta a puerta incluye aquellas actividades en las que el candidato se reúne con los residentes y visita sus casas y no aquellas en las que sólo participa un grupo de voluntarios o trabajadores pagados. Una vez más, es imposible medir el número de veces que el candidato realizó cada una de estas actividades y, por tanto, las variables dependientes son unidades binarias de 0 (cero), cuando el candidato no llevó a cabo cierta actividad, y de 1, cuando la actividad en cuestión fue realizada. La única actividad de campaña importante que se mencionó en varias entrevistas y que es imposible de medir con nuestras fuentes fueron los encuentros breves con líderes locales (con grupos de comerciantes, grupos de mujeres, campesinos, maestros o cualquier otro tipo de reunión vecinal).

Estudios de otros países y de algunos países miembros de la Unión Europea han recurrido a encuestas de los candidatos para investigar sobre las actividades de campaña. ${ }^{29}$ Este trabajo no utilizó encuestas por correo electrónico por dos razones. La primera es que es casi imposible conseguir las direcciones de los candidatos, puesto que la autoridad electoral nacional considera este tipo de información como privada. La segunda tiene que ver con el hecho de que algunos eventos que ocurren en las campañas están en el límite de lo legal, lo que dificulta que los candidatos sean muy comunicativos en una encuesta. No usamos cifras de gastos en este trabajo, dado que los partidos están legalmente autorizados para prorratear sus gastos de campaña, siempre y cuando los distribuyan entre los diferentes candidatos a diputado del partido.

$\& r c t=j \& q=\&$ esrc $=$ s \&source $=$ web $\& c d=12 \& v e d=0$ ahUKEwio-I7-p3YAhUB D2MKHezcDns4ChAWCC8wAQ\&url=http \% 3A\% 2F\% 2Feservicios. aguascalientes.gob.mx \% 2Ftransparencia\% 2FTransparenciaSolicitudes \% 2Fsolicitudes\% 2Farchivos\% 2F00002510_18032008_RESA.DOCX \&usg=AOvVaw3vRXj_SPm0sCvCqZ5n1RLv

${ }^{29}$ Bowler y Farrell, art. cit.; T. Zittel y T. Gschwend, "Individualised Constituency Campaigns in Mixed-Member Electoral Systems: Candidates in the 2005 German Elections", West European Politics, vol. 31, núm. 5, 2008, pp. 978-1003. 
Además, cabe considerar que los recursos de campaña en México con frecuencia son otorgados "en especie", por lo que para un mitin a los candidatos les prestan, por ejemplo, camiones y aparatos de luz y sonido. Muchos de estos recursos son ilegales y por esa razón se plantea que en lugar de considerar el dinero gastado es mejor medir los diferentes tipos de actividades que los candidatos llevaron a cabo.

En la tabla 2 se presenta un sumario estadístico del porcentaje de los candidatos en la muestra para el que se usó una gama de tácticas centradas en el candidato, como spots, sitios de redes sociales (páginas de Facebook y cuentas de Twitter), entrevistas en televisión por cable y periódicos, mítines y recorridos puerta a puerta. Si las campañas sólo estuvieran enfocadas en el partido, entonces los candidatos no llevarían a cabo actividades consideradas como típicas de las campañas centradas en los candidatos.

\section{TABla 2}

Diferentes tipos de actividades de campaña de los candidatos a diputados federales en 2009 y $2012^{\text {a }}$

\begin{tabular}{lccccc}
\hline & PAN & PRD & PRI & TOTAL & $\%$ \\
\hline Total de videos $^{\mathrm{b}}$ & 197 & 155 & 261 & 563 & 47 \\
Redes sociales & 206 & 171 & 290 & 667 & 56 \\
Entrevistas & 195 & 182 & 272 & 649 & 54 \\
Mítines & 213 & 168 & 348 & 729 & 61 \\
Campañas puerta a puerta & 248 & 209 & 344 & 804 & 67 \\
Total & & & & 1200 &
\end{tabular}

${ }^{\text {a }}$ De un total de 563 spots, 127 fueron producidos por el partido (22\%).

${ }^{\mathrm{b}}$ Datos obtenidos de Google, YouTube y de los recursos periodísticos de Infolatina.

Como puede apreciarse en la tabla, los candidatos de mayoría de México para la Cámara de Diputados a nivel federal están dispuestos a invertir tres meses para establecer una comunicación directa con los residentes de sus distritos. 
A continuación examinamos más detalladamente cada una de las actividades indicadas en ella.

\section{CAMPañas PUerta A PUerta}

En México, las campañas puerta a puerta, las reuniones y las visitas a los hogares de los vecinos son actividades intensas llevadas a cabo, sobre todo, pero no exclusivamente, por los candidatos y sus equipos. Una vez más, nuestra medida de las campañas puerta a puerta sólo incluye las actividades en las que el candidato estuvo presente y no aquellas que sólo involucraron al equipo del candidato. Curiosamente, recorrer las colonias supone una forma "moderna" de hacer campaña electoral en México, ya que ningún partido lo hacía (ni siquiera el PRI) durante el periodo hegemónico. Aproximadamente a principios de 1990, momento en que la competencia electoral empezó a crecer rápidamente, las visitas a hogares y los recorridos a pie se convirtieron en un baluarte de las elecciones modernas, pues, de acuerdo con varios entrevistados, "la gente quiere verte y estar en contacto directo contigo, pues eres el candidato". ${ }^{30}$ ¿Por qué? Porque "la política se ha vuelto más territorial (o más geográficamente situada)". Como lo muestra la tabla 2, el $67 \%$ de los candidatos a diputado hicieron campaña puerta a puerta durante sus recorridos. En la actualidad, los recorridos puerta a puerta consumen una buena parte del tiempo del candidato y su equipo: Jorge Hernández Hernández, diputado del PRI, dijo que caminó 14 kilómetros por día, tocando puertas, y que siguió un plan táctico muy estricto para evitar perder dinero o tiempo. Durante estos recorridos, los candidatos deben es-

${ }^{30}$ Entrevista con el diputado (Dr.) Hugo Rodríguez, el 13 de mayo de 2004. El entonces diputado Francisco Jiménez Merino mencionó que él mismo repartió volantes en las principales avenidas, porque había escuchado del efecto de multiplicación que tiene el contacto personal con los votantes en un curso sobre campañas electorales al que asistió en Miami (entrevista del 26 de mayo de 2004). 
cuchar las quejas de los ciudadanos sobre la falta o la poca calidad de los servicios públicos (temas sobre los que los candidatos no tienen ningún control). Los candidatos prometen negociar con las autoridades locales para ayudar a resolver estos problemas.

Durante las elecciones presidenciales y de diputados federales que se celebran de manera simultánea cada seis años, los equipos de campaña del Presidente contratan y pagan trabajadores para que ayuden a los candidatos con sus propias actividades de campaña, aunque en la práctica al equipo del Presidente sólo interesan unos cuantos cientos de municipalidades (de 2400 ), ${ }^{31}$ por lo que aquellos candidatos que estén fuera de esas áreas tendrán que esperar poca ayuda del partido nacional, incluso durante las elecciones simultáneas. Más aún, la mayoría de los candidatos entrevistados afirmaron que la organización local del partido no les ayudó a conseguir voluntarios para distribuir volantes ni para los recorridos a pie. Durante la época hegemónica, los sectores del PRI solían llevar a cabo distintas actividades de campaña en los distritos en los que tenían una presencia fuerte, pero hoy en día, salvo el Sindicato Nacional de Trabajadores de la Educación y el Sindicato de Trabajadores Petroleros de la República Mexicana, la mayor parte de las organizaciones corporativistas se han debilitado considerablemente.

\section{Mítines}

Este trabajo define los mítines como encuentros masivos al aire libre a los que asisten desde cientos hasta miles de personas para escuchar los discursos de candidatos. Usualmente, los asistentes son movilizados por el partido local, el alcalde o

31 Para más información sobre los viajes de campañas presidenciales, véase J. Langston y A. Benton, “A ras de suelo: apariciones de candidatos y eventos en la campaña presidencial de México”, Política y gobierno, vol. temático: "Elecciones en México", núm. 2, 2009, pp. 135-176. 
el candidato y a cambio de su participación esperan recibir transporte y comida. Los mítines son la actividad más costosa a la que pueden recurrir los candidatos de mayoría en México. Por lo general, tienen dos opciones: o bien pueden solicitar el apoyo de su partido local o estatal o bien pueden unir fuerzas con los otros candidatos que compiten en la misma área o en áreas colindantes.

Muchos de los políticos que entrevistamos -incluso los que pertenecen al PRI- afirmaron que no pensaban que los mítines fueran útiles. Sin embargo, más del $60 \%$ de los candidatos de nuestra muestra participaron en uno, el cual fue organizado por sus equipos o en conjunto con otros candidatos de su partido que también competían en la misma área, como el candidato a alcalde o a diputado local. Los argumentos en contra de los mítines son los mismos prácticamente en todas las entrevistas: los eventos masivos son costosos, porque hay que pagar grupos musicales, comida y transporte, y no hay manera de garantizar que los asistentes votarán por el candidato a cambio de una playera o de comida. Los asistentes tienen que recibir algún incentivo, ya no van sólo por convicción. Finalmente, los mítines conllevan ciertos riesgos para los candidatos, pues podrían ser abucheados o atraer sólo a un número reducido de asistentes, lo cual pondría en entredicho su popularidad o trabajo de campaña.

Sin embargo, como explica Szwarcberg, ${ }^{32}$ los mítines continúan cumpliendo una función en las democracias que recurren a tácticas clientelistas para movilizar a los votantes. De alguna manera, celebrar un mitin sirve para demostrarles a los líderes que los candidatos están cumpliendo con su trabajo, pues lograr que los residentes vayan a un mitin es similar al esfuerzo que hay que hacer para que los votantes vayan a las casillas de votación.

32 "Political Parties and Rallies in Latin America", Party Politics, vol. 20, núm. 3, 2014, pp. 456-466. 
SPOTS DE VIDEO

La Reforma electoral de 2008 prohibió a los candidatos la contratación y compra de publicidad en radio o televisión en las campañas de elecciones legislativas federales. En poco tiempo, los futuros diputados buscaron otros formatos para promover su imagen personal, lo cual puede ser considerado como otro indicio del deseo de los candidatos por comunicarse directamente con sus votantes. El servicio de streaming de videos de YouTube llegó a México en 2007 y para el 2009 los candidatos de mayoría ya habían utilizado videos para sus campañas. Los videoclips duraban entre treinta segundos y un par de minutos, mientras que algunos incluían música, gente bailando o simplemente mostraban una conversación en la oficina del candidato o sus encuentros con los vecinos. Otros spots sólo estaban constituidos por una serie de imágenes fijas o secuencias de video. En muchos de los videos se utilizaban tonadas pegajosas, pero en pocos se mostraba a los candidatos explicando sus políticas o programas específicos. En la mayoría de los spots, los candidatos hablaban de sus trayectorias profesionales, su familia y sus vínculos con la comunidad, así como de su deseo por llevar recursos federales al distrito. Con frecuencia, los videos pueden consultarse en la página electrónica del candidato, pero también pueden verse al buscar su nombre en el sitio de YouTube. Una parte reducida de los videos (22\%) se produjo con ayuda del gobernador o del partido nacional. La tabla 2 muestra que mientras el $40 \%$ de los candidatos en estos dos ciclos produjeron un spot de video promocional, sólo el $10 \%$ participó en un video producido por el partido. Por lo general, cuando los candidatos participan en un video producido por el partido, siguen un guion que cubre tanto su trayectoria profesional como sus atributos personales. 


\section{ENTREVISTAS PERSONALES EN PERIÓDICOS} Y PROGRAMAS DE INTERNET

Las entrevistas difundidas en televisión de paga y, en menor medida, en periódicos, se emplean más ahora que los candidatos no pueden contratar publicidad por radio (a causa de la Reforma electoral de 2008). Para las campañas analizadas en este artículo, internet aún no era un medio muy popular para la difusión de noticias; sin embargo, poco a poco se ha ido convirtiendo en la única vía que, además de los videoclips, permite a los candidatos dirigirse a un gran número de votantes. En México, los conductores de los programas de noticias que se transmiten por internet no suelen hacer preguntas contenciosas, sino que dejan que los candidatos tomen el control de la entrevista, al preguntarles acerca de sus intereses y propuestas. En la muestra, el $59 \%$ de los candidatos encontró espacios en televisión de paga o en periódicos para hablar directamente ante las cámaras.

Parece que todos los candidatos, tanto los que pierden como los que ganan, llevan a cabo actividades similares; sin embargo, los candidatos perdedores que entrevistamos tuvieron más problemas para obtener recursos y acceder a las redes políticas, lo que afectó la efectividad de sus campañas. Esos candidatos tampoco recibieron mucho dinero de los líderes de su partido y fue difícil para ellos persuadir a los intermediarios políticos locales de que se unieran a su campaña. Por lo general, la falta de recursos e intermediarios están detrás del fracaso de las campañas. A continuación, los modelos de regresión muestran que los candidatos tienden a llevar a cabo este tipo de actividades con menos frecuencia en distritos en los que históricamente su partido tiene pocas posibilidades de ganar. Los modelos también muestran que, cuando los candidatos tienen pocas posibilidades de ganar, emprenden menos tipos de actividades. 
VARIACIÓN DE LAS ACTIVIDADES DE CAMPAÑA EN LOS TREGIENTOS DISTRITOS DE MAYORÍA

Con el propósito de continuar analizando los argumentos del artículo, en esta sección se ponen a prueba las implicaciones empíricas de recurrir a las hipótesis antes señaladas para tratar de responder por qué mientras que algunos candidatos a diputado invierten el poco dinero, tiempo y energía que tienen en hacer campañas que movilicen a los votantes y promuevan su imagen, otros optan por no hacerlo. En primer lugar, si los candidatos de mayoría de México desean hablar de su trayectoria y sus planes con los votantes, entonces se puede esperar que aquellos con experiencia en puestos municipales y estatales sean más proclives a recorrer sus colonias distritales, dado que están más familiarizados con dichas localidades que los diputados que sólo han ocupado cargos en el escenario político nacional. Sin embargo, si el voto partidista incidiera significativamente en los resultados, entonces los cargos anteriores no deberían tener mucha importancia.

En segundo lugar, si los candidatos buscan un voto personal, aquellos que se encuentran en distritos de mayoría competitivos tendrán más probabilidad de hacer recorridos puerta a puerta, producir un video promocional y buscar oportunidades de ser entrevistados que aquellos que, o bien se encuentran en distritos en los que tienen pocas posibilidades de ganar (vid. infra), o bien están en los distritos que se consideran bastiones del partido. Si el voto partidista fuera más fuerte y los candidatos de mayoría no estimaran que es necesario entrar en contacto con los votantes, entonces las diferencias en los niveles competitivos no deberían importar, pues la publicidad del partido nacional difundida por la televisión debería llegar a todos los distritos. Finalmente, por el costo de los mítines, se esperaba que el PRI fuera el partido que organizara más de éstos a causa de la gran cantidad de gubernaturas que tuvo durante los años estudiados (aproxi- 
madamente el $65 \%$ de los estados tenían gobiernos priistas entre 2008 y 2012).

Este trabajo divide los trecientos distritos de mayoría del país en tres niveles de competitividad: perdido, bastión y competitivo. Estos niveles se miden al promediar el desempeño del partido entre 2003 y 2009. Los distritos perdidos son aquellos en los que el partido casi siempre ha sido derrotado por un margen de más del $5 \%$; los distritos competitivos son aquellos en los que el partido ha ganado o perdido por un margen del 5\%; los distritos bastión, en fin, son aquellos en los que históricamente el partido ha ganado por más del $5 \%$.

La variable indicadora del partido (PRI, PAN y PRD) mide las diferencias entre las organizaciones electorales mexicanas durante este periodo, especialmente las que tienen que ver con el financiamiento público de los partidos y con el tamaño de sus organizaciones partidistas. Se ha incorporado la trayectoria de los diputados de cada partido a los dos niveles de gobierno: subnacional y federal. Esto significa que si, por ejemplo, el candidato A tiene experiencia previa como alcalde y diputado local, el candidato será codificado con 1 en ambos puestos en la variable de experiencia subnacional. Los cargos estatales y municipales incluyen gobierno, partido estatal, congreso local, ayuntamiento, alcalde, gobierno de la ciudad y partido municipal. La experiencia federal comprende tanto el gobierno federal como los CEN. Esta distinción es importante, porque esperamos que aquellos diputados con experiencia subnacional usen más variedad de actividades que sus contrapartes que sólo tienen experiencia federal.

Una variable indicadora mide si se celebraron otras elecciones locales al mismo tiempo que las elecciones para diputados federales: se podría postular que, como circula más dinero cuando se celebran elecciones simultáneas, los candidatos deberían llevar a cabo más tipos de actividades. Usamos tres variables de control sociodemográfico que miden los niveles de educación, el porcentaje de zonas rurales en los dis- 
tritos y el número de habitantes por distrito que tiene acceso a servicios de salud, lo cual es importante, porque los habitantes de áreas más pobres por lo general no tienen electricidad en sus casas, ni mucho menos tienen computadoras y, por tanto, no son el público al que están dirigidos los spots difundidos en YouTube. Además, las regresiones incluyen una medida de cuántas zonas rurales hay en cada distrito. Por tanto, cuanto más alto sea el número positivo, más zonas rurales habrá en el distrito en cuestión. Empleamos controles de distrito, porque las actividades de campaña se desarrollan en distritos. También incluimos una variable para indicar si el candidato y el gobernador pertenecen al mismo partido, pues consideramos que estatalmente es la variable política más importante.

Si se leen transversalmente las regresiones logísticas que estiman las distintas actividades, es evidente que la competitividad de distrito y la experiencia previa inciden considerablemente en las probabilidades de que el candidato organice una actividad determinada. En el primer modelo de la tabla 3, en la página siguiente, examinamos qué tipo de candidato estaba más dispuesto a hacer campañas puerta a puerta en su colonia. La variable experiencia subnacional es positiva y significativa, pues indica si hay más probabilidades de que los candidatos con experiencia en este tipo de puestos recorran sus distritos que aquellos que no tienen experiencia subnacional. Lo anterior muestra la importancia que tiene regresar a la política subnacional para aquellos cuyas carreras surgieron en dicho nivel. Asimismo, tal y como se esperaba, la variable de la experiencia federal no es significativa, pues es más probable que aquellos con experiencia federal regresen al escenario nacional, por lo que tienen menos motivos para recorrer personalmente las colonias de sus distritos. 
TABla 3

Regresiones logísticas

\begin{tabular}{|c|c|c|c|c|c|}
\hline & & $\begin{array}{l}\text { Modelo } 1 \\
\text { Campañas } \\
\text { puerta a } \\
\text { puerta }\end{array}$ & $\begin{array}{c}\text { Modelo } 2 \\
\text { Spots de } \\
\text { video }\end{array}$ & $\begin{array}{c}\text { Modelo } 3 \\
\text { Entrevistas }\end{array}$ & $\begin{array}{c}\text { Modelo } 4 \\
\text { Mítines }\end{array}$ \\
\hline \multirow[t]{3}{*}{$\begin{array}{l}\text { Competencia a nivel } \\
\text { de distrito (no se } \\
\text { tomó en cuenta el } \\
\text { distrito perdido) }\end{array}$} & Competitivo & $0.55^{* *}$ & $0.68 * * *$ & 0.256 & $.42 * *$ \\
\hline & Bastión & 0.02 & $.32 *$ & $.39 * *$ & 0.004 \\
\hline & & 0.22 & 0.18 & 0.189 & 0.21 \\
\hline \multirow{3}{*}{$\begin{array}{l}\text { Experiencia del } \\
\text { candidato }\end{array}$} & & & & & \\
\hline & Subnacional & $\begin{array}{l}0.55^{* *} \\
0.22\end{array}$ & $\begin{array}{l}0.146 \\
0.145\end{array}$ & $\begin{array}{l}.297 * * \\
0.15\end{array}$ & $\begin{array}{r}.28^{*} \\
0.166\end{array}$ \\
\hline & Federal & $\begin{array}{l}0.39 \\
\{.27\}\end{array}$ & $\begin{array}{l}.55^{* *} \\
0.23\end{array}$ & $\begin{array}{c}.42^{*} \\
0.24\end{array}$ & $\begin{array}{l}0.33 \\
0.25\end{array}$ \\
\hline \multicolumn{2}{|l|}{ mismo partido } & $\begin{array}{l}-0.015 \\
-0.188\end{array}$ & $\begin{array}{l}0.25 \\
0.159\end{array}$ & $\begin{array}{l}0.083 \\
0.166\end{array}$ & $\begin{array}{l}0.359 * * \\
0.18\end{array}$ \\
\hline $\begin{array}{l}\text { Presidente } \\
\text { municipal del } \\
\text { mismo partido }\end{array}$ & & $\begin{array}{l}.53^{* * * *} \\
0.19\end{array}$ & $\begin{array}{l}0.25 \\
0.162\end{array}$ & $\begin{array}{l}0.03 \\
0.17\end{array}$ & $\begin{array}{l}.79 * * * \\
0.187\end{array}$ \\
\hline \multicolumn{6}{|l|}{$\begin{array}{l}\text { Partido } \\
\text { (no se tomó en }\end{array}$} \\
\hline \multirow{3}{*}{ cuenta el PAN) } & & 0.157 & 0.151 & -0.15 & 0.152 \\
\hline & PRI & $1.32 * * *$ & $0.455^{* * *}$ & $.74 * * *$ & $1.58 * * *$ \\
\hline & & 0.2 & 0.16 & 0.17 & 0.182 \\
\hline Año de la elección & 2012 & $.47 * * *$ & $.255^{* * *}$ & -0.03 & 0.02 \\
\hline \multicolumn{2}{|c|}{ (no se tomó en cuenta el 2009) } & 0.14 & 0.124 & 0.128 & 0.136 \\
\hline \multirow{2}{*}{\multicolumn{2}{|c|}{ Elección simultánea }} & $-1.53 * * *$ & $-0.779 * * *$ & -1.5 & $-0.83 * * *$ \\
\hline & & 0.16 & 0.132 & 0.14 & 0.145 \\
\hline \multirow{2}{*}{\multicolumn{2}{|c|}{ Zonas rurales }} & -0.016 & $-0.749 * * *$ & $-0.42 * *$ & 0.345 \\
\hline & & 0.26 & 0.23 & 0.23 & 0.25 \\
\hline \multirow{2}{*}{\multicolumn{2}{|c|}{ Servicios de salud }} & $2.8^{* * *}$ & $1.46^{* *}$ & $3.02 *$ & 0.28 \\
\hline & & 0.8 & 0.66 & 0.7 & 0.725 \\
\hline \multirow{2}{*}{\multicolumn{2}{|c|}{ Constante }} & $1.06^{* *}$ & -0.87 & $-1.3^{* * *}$ & -0.16 \\
\hline & & 0.516 & 0.46 & 0.47 & 0.5 \\
\hline \multicolumn{2}{|c|}{ Número de observaciones } & 1200 & 1200 & 1200 & 1200 \\
\hline \multicolumn{2}{|l|}{ Pseudo r cuadrada } & 0.182 & 0.091 & 0.125 & 0.184 \\
\hline
\end{tabular}


GráficA 2

Probabilidad de que los candidatos hagan campañas puerta a puerta dada la competitividad distrital y la experiencia previa a nivel subnacional

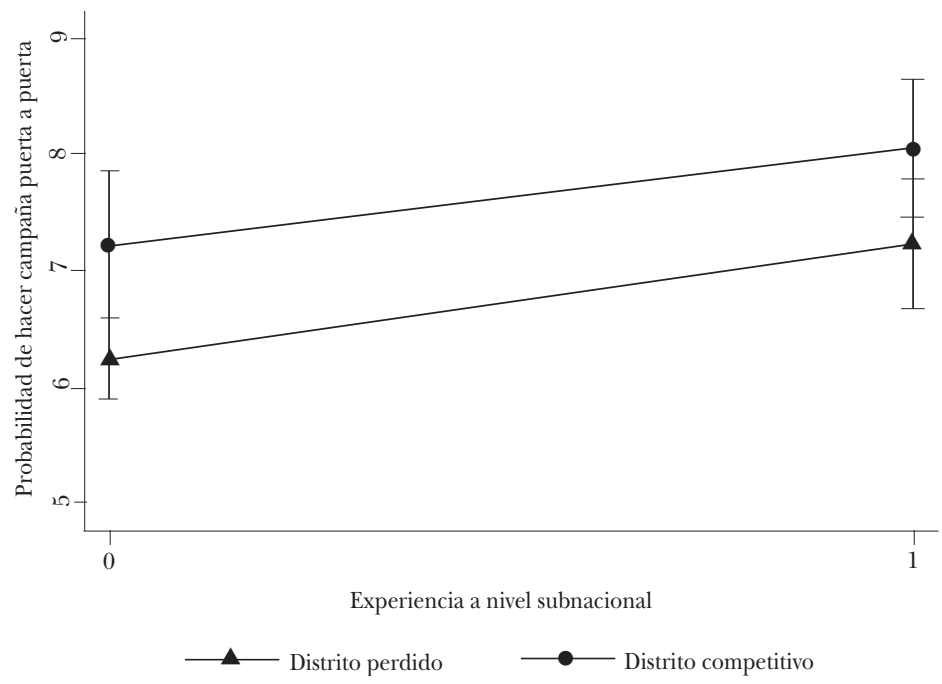

Fuente: Modelo 1 de regresión logística.

Como puede verse en la gráfica de arriba, es más probable que los candidatos en distritos competidos recorran sus colonias para acercarse a los votantes que los candidatos que se encuentran en distritos que se tienen por perdidos. Es aún más probable que los candidatos que cuentan con experiencia en puestos a nivel subnacional y que están en campaña en un distrito perdido hagan campañas puerta a puerta que aquellos que no tienen experiencia previa en puestos municipales o estatales. La probabilidad de hacer campañas puerta a puerta se incrementa sustancialmente (el triángulo en la gráfica 2), si el candidato que se encuentra en un distrito perdido tiene un puesto a nivel subnacional. La probabilidad más alta de que se lleven a cabo campañas puerta a puerta corresponde a los candidatos que tienen experiencia en el 
ámbito subnacional y que contienden en un distrito competitivo: su probabilidad supera el $80 \%$, frente al $62.5 \%$ para aquellos candidatos que no tienen un puesto local y que están compitiendo en un distrito perdido. Así, mientras que la experiencia en puestos subnacionales y el nivel de competitividad del distrito influyen en la probabilidad de que se lleven a cabo campañas puerta a puerta, la experiencia federal no es un factor.

La producción de spots de video no requiere de mucho dinero, pero sí de un claro deseo de acercarse a los votantes de una manera más personal, que les permita conocer mejor a su representante. A la inversa de lo que se esperaba, la experiencia federal es positiva y significativa, lo cual puede deberse a que los candidatos con experiencia en el ámbito nacional se sienten más cómodos con las nuevas tecnologías y tienen más acceso a los productores de éstas. La competencia en el distrito desempeña un papel importante en el modelo 2, que concierne a los spots de video ${ }^{33}$ producidos por el candidato: es más probable que los candidatos que hacen campaña en distritos competidos y bastiones publiquen un video que ellos mismo hayan producido.

En la gráfica 3, puede observarse que la probabilidad de que un candidato haga un video es más elevada, cuando tiene experiencia federal y se encuentra en un distrito competido. También es interesante observar que, en el caso de los candidatos sin experiencia federal (cuadrante inferior izquierdo), el nivel de competencia del distrito tiene un efecto importante en la producción de un video, pues los intervalos de confianza no se sobreponen. Es más probable que los candidatos con experiencia federal previa produzcan un video, cuando hacen campaña en un distrito competido, que cuando lo hacen en un distrito que se considera perdido (la línea con el triángulo). Una vez más, es menos probable que aquellos que no

33 No se tomaron en cuenta los videos caseros que se difundieron sin ningún texto, voz en offo música. Sin embargo, sólo encontramos 27 videos con estas características de una muestra de 1 200. Véase supra tabla 2. 
GRÁFICA 3

Videos hechos según la experiencia federal previa y el nivel de competencia en el distrito

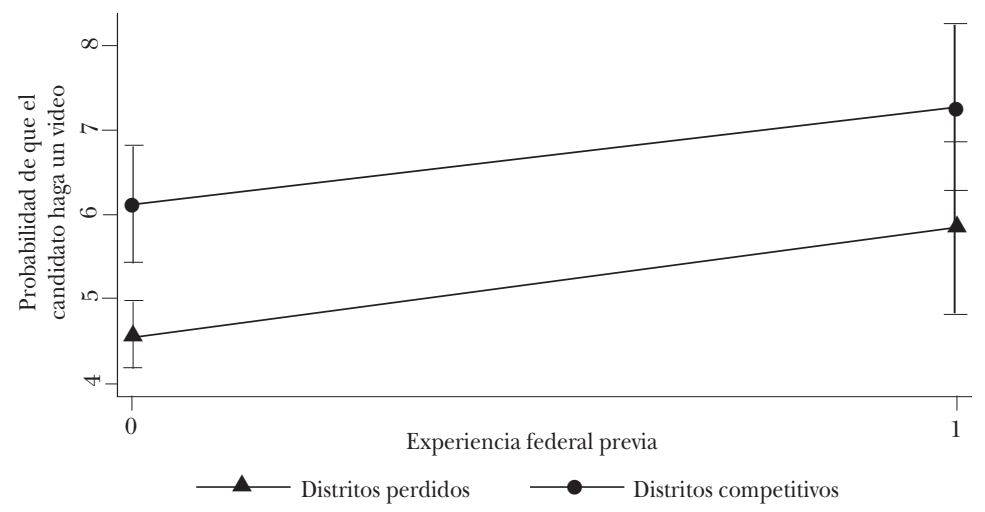

Fuente: Modelo 2 de regresión logística.

han ocupado un cargo federal en un distrito perdido realicen un video que aquellos que sí han ocupado cargos en la escena nacional y que están haciendo campaña en un distrito competido. La probabilidad aumenta del 44.5 al $71.5 \%$, respectivamente.

Aunque no se muestra en la gráfica a que aludo, es menos probable que los candidatos del PRD hagan sus propios videos, quizás porque muchos de ellos hicieron campaña en distritos perdidos. Si bien en 2009 el partido de centro-izquierda produjo muchos videos de cada uno de los candidatos de distrito, en los que usó plantillas y diálogos similares, en 2012 no lo hizo así. Parece que para las elecciones de 2012 muchos de los candidatos de todos los partidos se habían enterado de los videos y empezaron a publicar más, tal y como lo indica el signo positivo y significativo en el coeficiente.

Las entrevistas individuales que se publican en los medios impresos o digitales son sin duda una herramienta valiosa para promover el voto personal, pues el candidato puede hablar directamente con los lectores sobre su trayectoria y 
promesas, con la única mediación del entrevistador. Notamos que la experiencia en los escenarios subnacional y federal incide en la probabilidad de que un diputado se dirija a los votantes -mediante un entrevistador-por medio de internet o las ondas sonoras. El nivel de competencia del distrito también afecta esta probabilidad, lo cual significa que es más probable que los candidatos sean entrevistados en aquellos distritos considerados como bastión del partido, pues los candidatos se esfuerzan para buscar entrevistas, cuando están compitiendo para ganar y cuando están haciendo campaña en un distrito-bastión.

\section{GRÁFICA 4}

Entrevistas por nivel de competencia y experiencia subnacional

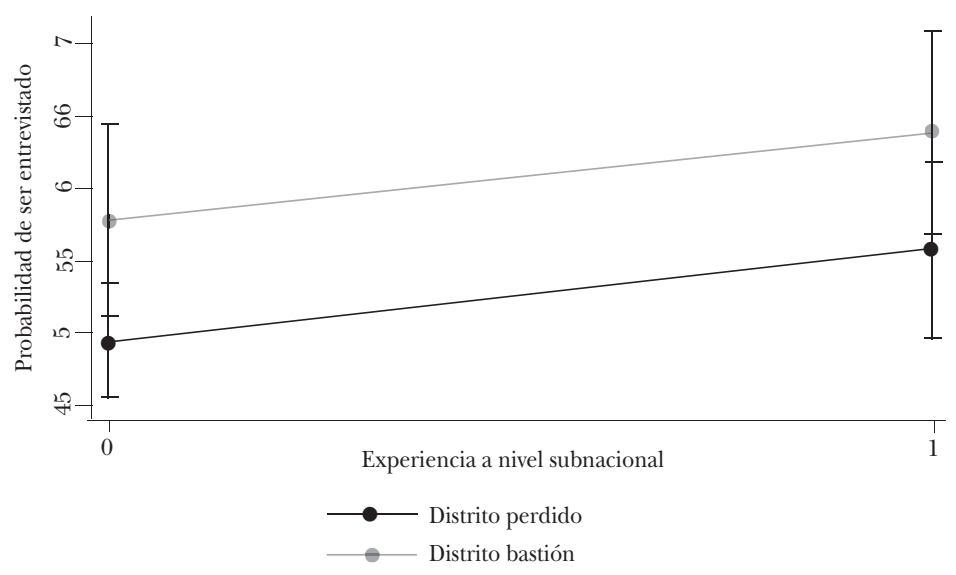

Fuente: Modelo 3 de regresión logística.

Los candidatos del PRI son más habilidosos para conseguir entrevistas (sin pagar formalmente por ello) que los candidatos del PAN (la categoría excluida), lo cual puede deberse a que es más fácil para el PRI acceder a la red local de productores que para sus contrapartes de otros partidos. 
Los mítines son costosos y requieren de mucha planeación para que sean exitosos. Por tanto, los alcaldes o los gobernadores del partido (véase la regresión anterior) o incluso el propio partido del candidato suelen encargarse de organizarlos. El modelo 4 en la gráfica siguiente cubre la probabilidad de que se celebre un mitin. Si el distrito es competitivo para el partido del candidato, entonces es más probable que haya un mitin. Si bien su impacto en esta variable fue débil, la experiencia subnacional también incidió en que los candidatos participaran o no en un mitin.

\section{GRÁFICA 5}

Mítines por grado de competencia en el distrito

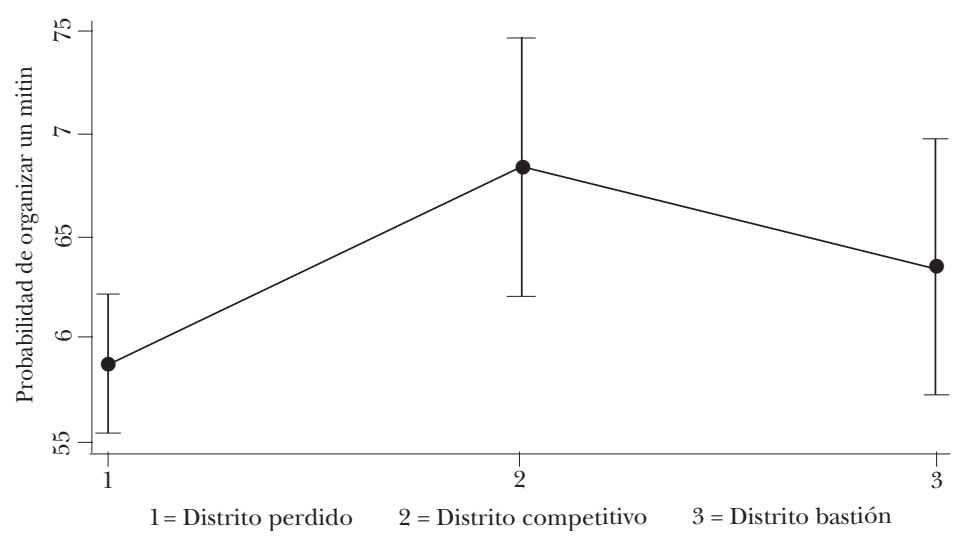

Fuente: Modelo 3 de regresión logística.

Los datos disponibles sobre las campañas puerta a puerta, spots de video, entrevistas y mítines han confirmado muchas de las hipótesis formuladas en este trabajo. El número de votantes partidistas en un distrito -según el promedio histórico del voto partidista en ese distrito- propició que los candidatos a los DEU tuvieran más disposición o no para llevar a cabo campañas puerta a puerta, publicar sus propios videos y participar en entrevistas que promovieran su experiencia y sus 
capacidades personales. Este hallazgo es importante, porque significa que la trayectoria personal de los candidatos puede tener un impacto en el tipo de campaña que llevarán a cabo, lo cual no era de esperar, si se toma en cuenta que los votantes parecen no saber mucho de las personas que los representan en la Cámara de Diputados, ni sobre lo que hacen sus representantes una vez que están en el cargo. Los candidatos con más experiencia, por lo general, tienden a hacer campañas más activas, personales y con más tecnología y el tipo de trayectoria con más valor es la que se ha desarrollado en la política subnacional.

\section{Conclusiones}

A pesar de que las leyes constitucionales y electorales deberían dificultar la realización de campañas personalistas y centradas en los candidatos, los candidatos a diputados federales de México han recurrido a herramientas modernas e individualizadas para comunicarse con sus votantes locales. Especialmente han usado spots de video, campañas puerta a puerta y entrevistas. Las oficinas nacionales de los partidos también han desempeñado un papel activo en este sentido, sobre todo al promover las campañas a nivel nacional y, en menor medida, al participar en trabajos de movilización en los trecientos distritos de mayoría del país. En este artículo, se ha argumentado que los motivos por los cuales los candidatos están dispuestos a pasar tres meses de trabajo intenso guardan una relación estrecha con la ambición de seguir una carrera política y una manera factible de hacerlo es regresar al escenario subnacional. Además, dado que las leyes electorales prohíben comprar publicidad, los candidatos han recurrido a otras alternativas más baratas, como las campañas puerta a puerta, la búsqueda de entrevistas y la producción de videos en los que muestran a sus familias, sus vínculos con la comunidad y sus proyectos para llevar recursos federales a la localidad. 
Los candidatos invierten en distintas actividades de campaña, dado que pueden aprovecharlas para ganar las elecciones y fundar una base personal de apoyo con los votantes locales y los líderes políticos. Muchos políticos empiezan su trayectoria en el ámbito municipal y estatal, y suelen volver a estos espacios al terminar su primer mandato en la Ciudad de México. Este tipo de trayectoria profesional crea incentivos para aquellos diputados que esperan contribuir a fortalecer el voto partidista y, al mismo tiempo, tratan de conseguir apoyo gracias a sus cualidades y calificaciones personales. Esta es una reacción racional en un ambiente en el que los partidos nacionales continúan reduciendo los espacios y los recursos para que los candidatos promuevan de manera activa su imagen.

Los líderes de partido tienen otros incentivos, entre los que descuella conseguir el número más elevado de victorias distritales y ganar tantos escaños como sea posible en las cinco circunscripciones de mayoría del país. Los candidatos sólo quieren ganar sus contiendas distritales. En consecuencia, los incentivos de los líderes de partido deben tomarse en cuenta, cuando se estudian las campañas electorales. La importancia de las normas institucionales parece indudable. Sin embargo, los líderes de partido y sus preferencias también importan, pues ayudan a determinar las acciones de los partidos. Al tomar en cuenta a los candidatos y los líderes del partido, este artículo ha identificado un tipo de campaña legislativa que la mayoría de los artículos académicos sobre el tema no han tratado. Esta campaña supone un estilo mixto que combina candidatos que trabajan de manera intensa para promover su identidad por medio de diversas actividades de campaña y una muy activa organización partidista a nivel nacional que decide, produce y transmite las propuestas programáticas mayores en los medios nacionales.

\section{Trad. de Tania P. Hernández-Hernández $e$ IVÁN ÁLVAREZ}




\section{BibLIOGRAFÍA}

Bowler, Shaun y David M. Farrell, "Electoral Institutions and Campaigning in Comparative Perspective: Electioneering in European Parliament elections", European Journal of Political Research, vol. 50, núm. 5, 2011, pp. 668-688.

Cain, Bruce, John Ferejohn y Morris Fiorina, The Personal Vote. Constituency Service and Electoral Independence, Cambridge, Harvard University Press, 1987.

Canache, Damarys, Jeffery Mondak y Ernesto Cabrera, "Voters and the Personal Vote: A Counterfactual Simulation”, Political Research Quarterly, vol. 53, núm. 3, 2000, pp. 663-679.

Carey, John M. y Matthew S. Shugart, "Incentives to Cultivate a Personal Vote: A Rank Ordering of Electoral Formulas”, Electoral Studies, vol. 14, núm. 4, 1995, pp. 417-439.

Cox, Gary W. y Mathew D. McCubbins, Legislative Leviathan. Party Government in the House, Berkeley-Los Angeles, CA, University of California Press, 1993.

Daniel, Kermit y John R. Lott Jr., "Term Limits and Electoral Competitiveness: Evidence from California's State Legislative Races”, Public Choice, vol. 90, núms. 1-4, 1999, pp. 165-84.

Díaz Jiménez, Oniel Francisco, "Marketing político y profesionalización de las campañas electorales del Partido Acción Nacional y el Partido de la Revolución Democrática (1994-2006)”, Polis, vol. 11, núm. 1, 2015, pp. 119-168.

Eaton, Kent, "Political Obstacles to Decentralization: Evidence from Argentina and the Philippines", Development and Change, vol. 32, núm. 1, 2001, pp. 101-127.

"Entrevista a María de las Heras, otrora experta de encuestas del PRI", 22 de noviembre de 2001.

"Entrevista a Sandoval, diputado del PRI", abril de 2002.

"Entrevista a Lázaro Arias, diputado del PRI", 6 de mayo de 2004.

"Entrevista a Raúl Mejía, diputado del PRI", 27 de mayo de 2004.

"Entrevista a Mario Zepahua, diputado del PRI", 31 de mayo de 2004.

"Entrevista a Humberto Cervantes, del PRI", 1 de junio de 2004.

"Entrevista a Jesús María Ramón, exdiputado del PRI en Puebla", 15 de junio de 2004. 
"Entrevista a Norberto Corella, diputado del PAN", 23 de febrero de 2005.

"Entrevista a Gustavo Madero, diputado federal", 2 de marzo de 2005.

"Entrevista a María Araceli Vázquez Camacho, diputada federal", 10 de junio de 2010.

"Entrevista a María de la Paz Quiñones, diputada federal", 14 de junio de 2010.

Exeni, José Luis, "Acción mediática en tiempo de elecciones", en Yolanda Meyenberg (coord.), Dos de julio: reflexiones posteriores, México, FLACSO-IIS-UAM-I, 2001.

Flamand, Laura, The Vertical Dimension of Government: Democratization and Federalism in Mexico, Rochester, University, 2004.

Gelman, Andrew y Gary King, "Estimating Incumbency Advantage without Bias", American Journal of Political Science, vol. 34, núm. 4, 1990, pp. 1142-1164.

Giraudy, Augustina, "The Politics of Subnational Undemocratic Regime Reproduction in Argentina and Mexico", Journal of Politics in Latin America, vol. 2, núm. 2, 2010, pp. 53-84.

Hernández Rodríguez, Rogelio, El centro dividido: la nueva autonomía de los gobernadores, México, El Colegio de México, 2008.

INE: Instituto Nacional Electoral, Memorias del Proceso Electoral Federal 2011-2012, en www.ine.mx

Karp, Jeffrey A. y Susan A. Banducci, "Party Mobilization and Political Participation in New and Old Democracies", Party Politics, vol. 13, núm. 2, 2010, pp. 217-234.

Kerevel, Yann, “(Sub)national Principals, Legislative Agents: Patronage and Political Careers in Mexico", Comparative Political Studies, vol. 48, núm. 8, 2015, pp. 1020-1050.

Langston, Joy y Allyson Benton, "A ras de suelo: apariciones de candidatos y eventos en la campaña presidencial de México", Política y gobierno, vol. temático: "Elecciones en México", núm. 2, 2009, pp. 135-176.

Mayhew, David, Congress: The Electoral Connection, New Haven, Yale University Press, 1974.

Meneses Rocha, María Elena y Jacob Bañuelos Capistrán, Internet y campañas electorales en México. La oportunidad postergada, Toluca, 
Instituto Electoral del Estado de México, 2009 (Serie Breviarios de Cultura Política Democrática, núm. 8).

Samuels, David, "Incentives to Cultivate a Party Vote in Candidatecentric Electoral Systems”, Comparative Political Studies, vol. 32, núm. 4, 1999, pp. 487-518.

—., Ambition, Federalism, and Legislative Politics in Brazil, Nueva York, Cambridge University Press, 2003.

Shugart, Matthew y Martin Wattenberg, Mixed-Member. Electoral Systems. The Best of Both Worlds?, Nueva York-Oxford, Oxford University Press, 2001.

Szwarcberg, Mariela, "Political Parties and Rallies in Latin America”, Party Politics, vol. 20, núm. 3, 2014, pp. 456-466.

Tello-Leal, Edgar, Diego Armando Tello-Leal y Claudia Maricela Sosa Reyna, "Reflexiones sobre el uso de las tecnologías de información y comunicación en las campañas electorales en México", Revista Virtual Universidad Católica del Norte, núm. 36, 2012, pp. 33-47.

Tosoni, María Magdalena, "Notas sobre el clientelismo político en la Ciudad de México”, Perfiles Latinoamericanos, vol. 29, núm. 1, 2007, pp. 47-69.

Zittel, Thomas y Thomas Gschwend, "Individualised Constituency Campaigns in Mixed-Member Electoral Systems: Candidates in the 2005 German Elections”, West European Politics, vol. 31, núm. 5, 2008, pp. 978-1003. 


\section{APÉNDICE \\ Sumario de estadísticas}

\begin{tabular}{lccc}
\hline Nombre de la variable & Observaciones & Promedio & $\begin{array}{c}\text { Desviación } \\
\text { estándar }\end{array}$ \\
\hline Candidatos & 1200 & $*$ & 300.50 \\
Experiencia en el gobierno municipal & 1200 & 0.50 & 0.5 \\
Experiencia en el gobierno estatal & 1200 & 0.51 & 0.50 \\
Experiencia en el gobierno federal & 1200 & 0.72 & 0.28 \\
Distrito perdido & 1200 & 0.59 & 0.49 \\
Distrito competido & 1200 & 0.26 & 0.44 \\
Distrito bastión & 1200 & 0.16 & 0.36 \\
Uso de las redes sociales & 1200 & 0.55 & 0.49 \\
Producido de manera individual en YouTube & 1200 & 0.40 & 0.49 \\
Producido por el partido en YouTube & 1200 & 0.10 & 0.29 \\
Actividades de campaña puerta a puerta & 1200 & 0.66 & 0.47 \\
Mitin & 1200 & 0.61 & 0.49 \\
Entrevistados & 1200 & 0.59 & 0.58 \\
PAN & 1200 & 0.33 & 0.47 \\
PRD & 1200 & 0.33 & 0.47 \\
PRI & 1200 & 0.33 & 0.47 \\
Gobernador del mismo partido & 1200 & 0.34 & 0.47 \\
Nominación democrática & 1167 & 0.42 & 0.49 \\
Educación de la mujer (en años) & 1200 & 8.27 & $*$ \\
Servicios de salud & 1200 & .647 & $*$ \\
\hline
\end{tabular}


